\title{
Non-Interactive Amblyopia Treatment Modalities in Children: A Systematic Review and Meta-Analysis
}

Mohammed Seid Hussen ( $\nabla$ mohamiaseid@gmail.com )

University of Gondar

Nebiyat Feleke Adimassu

University of Gondar College of Medicine and Health Sciences

Gizachew Tilahun Belete

University of Gondar College of Medicine and Health Sciences

Asmamaw Atnafu

University of Gondar College of Medicine and Health Sciences

\section{Research article}

Keywords: Amblyopia Treatment, Atropine versus patching, Children

Posted Date: August 7th, 2020

DOl: https://doi.org/10.21203/rs.3.rs-28320/v2

License: (c) (i) This work is licensed under a Creative Commons Attribution 4.0 International License. Read Full License 


\section{Abstract}

Background: Recently, a number of clinical trials are conducting on amblyopia treatments. Discovering an intervention that provides optimal outcome with minimal subsidiary effect is an essential issue in medical arena. Therefore, this review aimed to identify the most effective and safest amblyopia interventions in an integrative manner.

Methods: Eligible studies were identified from Cochrane library (CENTRAL), PubMed Central, Google Scholar, ScienceDirect, and Scopus electronic database. Data pooling was performed for trials with a little statistical heterogeneity $(P>0.05,12<50 \%)$ using the fixed-effect models. The mean difference (MD) and risk ratio (RR) at $95 \%$ confidence interval $(\mathrm{Cl})$ for visual acuity improvement, the success of the treatment, reverse amblyopia, and adherence rate was pooled.

Results : Eight trials consisted of 1253 participants were included. The pooled mean visual acuity improvement was similar for both six hours and full time patching (MD, $0.00 ; 95 \% \mathrm{Cl},-0.54$ to 0.55$)$. In subgroup analysis, all spectrum of patching are equally effective in treating mild to moderate amblyopia but 6 hours to full-time patching regimen are effective for severe amblyopia. The therapeutic outcome of patching was statistically preferable to atropine (pooled MD, 0.25 lines; $95 \% \mathrm{Cl}, 0.01$ to 0.48 ). Besides, the incidence of reverse amblyopia was lower in patching groups as compared to atropine (pooled RR, $0.19 ; 95 \%$ $\mathrm{Cl}$ : 0.06 to 0.57 ). However, the treatment adherence for patching was lesser, (pooled RR, $0.9 ; 95 \% \mathrm{Cl}, 0.84$ to 0.96 ).

Conclusion: Patching, particulary six-hours patching as a first line treatment provides optimal visual acuity improvement that balances the effect of reverse amblyopia and poor adhrence as compared to atropine and other spectrum of patching regimen but it should be under proactive monitoring to optimize the adherence issues.

\section{Background}

Amblyopia ('Lazy eye') is the second most common cause of functional low vision in children in Low- and medium-income countries. ${ }^{1}$ The prevalence of amblyopia in children is ranged from $0.74 \%-4.6 \% .{ }^{2-7}$ The condition is a unilateral or infrequently bilateral condition, which is caused by abnormal development of the visual system associated with strabismus, refractive error, and visual deprivation during the critical period of visual development (up to the age of 7 years). 5,8 Basically, the development of the visual system depends on the sensory input during the critical period when there is active neuroplasticity. If there is abnormal visual stimuli/input to the primary visual cortex from the two eyes, the normal binocular interaction and development of spatial processing can be disrupted. This results in loss of stereopsis, visual acuity, and contrast sensitivity. ${ }^{9}$ Some studies reported that morpho-physiological changes to the neural cells such as enlargement of receptive field size, disorganization of a topographical map, reduction of the complement of cortical cells, and reduction of cortical magnification can occur. ${ }^{10,11}$ If the intervention is not given before the cessation of the critical period, the amblyopia will persist into adulthood. The lifetime risk of binocular visual impairment was $18 \%$ for amblyopic persons, whereas for non-amblyopic individuals, it was $10 \%{ }^{12}$

As diagnostic criteria, unilateral amblyopia is defined as a difference in best-corrected visual acuity (BCVA) between the two eyes of 0.2 log MAR (logarithm of the minimum angle of resolution with base ten) or 2 line difference. For children aged less than 3 years, asymmetric objection, or failure to maintain fixation, an intraocular difference of $\geq 2$ octaves in preferential looking of Teller acuity are indicators of unilateral amblyopia. Bilateral amblyopia is defined as a reduction of $0.2 \log$ MAR or more compared with the developmental norms for BCVA at a given age. ${ }^{8,13}$

Since the severity of amblyopia has effect on management protocol, amblyopia is classified as moderate (distance BCVA $\geq 6 / 24$ or $\geq 0.60$ log MAR) and severe (distance $B C V A<6 / 24$ or $<0.60 \log M A R$ ) ${ }^{14,15}$. The mechanism of amblyopia treatment is based on the initiation of amblyopic eye by limiting the function of sound eye. The neural basis of the treatment is related to the phenomenon of neuroplasticity, which is mediated by the action of neuromodulators that promote long-term synaptic changes ${ }^{16}$. Patching of the fellow eye and providing visual stimuli to the amblyopic eye can remodel the cortical functions

${ }^{17}$. Besides, morphologic changes in cells of the retina, lateral geniculate nucleus, and visual cortex are occurred ${ }^{18}$

The target of amblyopia treatments is to equalize the visual function of the two eyes, which is commenced after treating the underlying cause and the visual acuity is stabilized with optical correction for a minimum of 4 months. ${ }^{19}$ Recently, numerous clinical trials are being conducted on the effectiveness and safeness of passive amblyopia treatments, particularly PEDIG trials. Several studies reported that the success of amblyopia treatment varies from $30 \%$ $-92 \% .{ }^{20-23}$ Factors behind the success were patient compliance, high refractive error, the magnitude of anisometropia, and severity of amblyopia, age at the time intervention, the dose of treatment, eccentric fixation, binocularity and type of amblyopia. ${ }^{20,24-26}$ A review article that compared atropine with patching has recommended atropine penalization as a first line treatment ${ }^{27}$. Another study also compared that Part-time with full-time patching and concluded that both are equally effective ${ }^{28}$. The conclusion these reviews was focused on the therapeutic effect with little consideration of secondary outcomes such as reverse amblyopia and treatment adherence even though studies reported that the reverse amblyopia and compliance for treatment particularly patching were refractory to treatment. $29,30,31$

Assuring overweighting of the benefit over the adverse effect is an essential step to choose a modality. Overall previous reviews are unidirectional and significant attention for visual acuity stabilization with optical correction was not given. ${ }^{31-33}$ Hence, this review was aimed to generate evidence on therapeutic and adverse effects of amblyopia interventions in an integrative manner which assists the clinicians in managing amblyopic patients and researchers to develop new hypothesis.

\section{Methods}

\section{Protocol}




\section{Study Eligibility Criteria}

For this review, articles with the characteristics of randomized controlled trials (RCTs), peer-reviewed articles published in English language were considered. As eligibility criteria, studies conducted on children diagnosed with strabismic amblyopia, anisometropic amblyopia, or mixed amblyopia with no prior amblyopia treatment other than spectacles. Moreover, the spectacle correction should be followed for at least 18 weeks, through which visual acuity improvement would be stabilized before enrollment. Functional amblyopia is the most common and treatable type of amblyopia, which is caused by childhood strabismus, anisometropia, or mixed. Hence, children with organic amblyopia associated with ocular pathology or surgical intervention for other ocular disease were not included because such kind of conditions can mask of the effect of amblyopia intervention. However, pilot studies, ongoing trials, retrospective record reviews, review articles, trials for residual amblyopia (have a history of prior treatment of amblyopia other than spectacle) were excluded. Limitation of language literacy and inaccessibility of the articles from the standard search engine were the reason to exclude articles published in a language other than English.

\section{Search methods}

The studies were identified from electronic databases searching such as Cochrane Central Register of Controlled Trials (CENTRAL)', PubMed Central, Google Scholar, ScienceDirect and Scopus between 08//2018 to 8/2019. Keywords such as 'amblyopia', 'patching', 'atropine', and "occlusion" were used to look for articles from the database. Additional trials were manually searched.

\section{Selection of studies and data extraction}

Initially, two authors independently assessed the titles and abstracts of the articles after duplicated records were ruled out. Disagreements between the two authors were alleviated through discussion in the presence of the third author. Each abstract was labeled as 'included' and 'excluded' after the abstract screening. Then full-text review was performed by all authors independently. For included studies, all relevant data were extracted using data extraction form, which was developed using Cochrane data collection form for intervention reviews(RCTs and non-RCTs) guideline. ${ }^{35}$ The form consisted of the journal name, publication year, aim of the study, unit of allocation, study design, inclusion and exclusion, age, participants, sex, follow up duration, type of amblyopia, the severity of amblyopia, intervention type, type of comparison, outcome measures, the effect of the intervention, adverse effects, adherence and conclusion of the studies. The extracted data were compared between the authors and any discrepancy was resolved together.

\section{Types of outcome measures and data item}

Comparison of patching with atropine and part-time patching (Six hours per day) with full-time patching (more than10 hours per day and all waking hours per day) were considered. The primary outcomes were the mean visual acuity improvement from the baseline in the amblyopic eye (in log MAR line) and improving visual acuity of amblyopic eyes by $\geq 2 \log$ MAR lines from the baseline (Success rate). Since the improvement of 2 or more lines of visual acuity had good statistical power to detect treatment difference and minimize chance as compared to other dichotomous criteria (better than 20/25, better than $20 / 32$, equal vision in both eyes, and improved 3 or more lines), it was considered as a criterion to measure success. ${ }^{36}$ The secondary outcomes were adherence rate and significant reverse amblyopia (reduction of visual acuity in the sound eye by $\geq 2$ Log MAR lines from the baseline in the sound eye). ${ }^{13}$ So many studies defined treatment adherence rate as excellent (76\%-100\% of prescribed treatment completed), good (51\%-75\%), fair (26\%-50\%) and poor ( $\leq 25 \%)$ based on the author judgment. ${ }^{37-39}$ Since the frequency was too small in this review, this classification was modified as good adherence (51\%-100\%) and Poor adherence $(\leq 50 \%)$. Visual acuity reported in the form of letters was converted into a number of lines. A single letter of the Log MAR chart is valued as 0.02. The numbers of letters per row of a log MAR chart are five letters. Thus, the value of a log MAR line is 0.1 log MAR unit ( $0.02 \times 5$ letters). Five log MAR letters improvement from the baseline is equivalent to one line improvement. The standard deviation of the mean improvement reported in letter form was changed into line by dividing the number of letters by five.

\section{Assessment of risk of bias within and across studies}

Three authors assessed the risk of bias using the validated Cochrane collaboration tool. ${ }^{40}$ The parameters were random sequence generation; allocation concealment; masking (blinding) of outcome assessors; blinding of the participants; incomplete outcome data; selective outcome reporting; and other sources of bias. Finally, each trial was labeled as 'low risk of bias,' unclear risk' and 'high risk of bias 'with supporting evidence. Publication bias was also evaluated using funnel plots and statistically by Egger's regression intercepts method. 


\section{Data synthesis and Summary measures}

The treatment effect was estimated using mean difference (MD) for visual acuity change from the baseline and Risk ratio (RR) for incidence of reverse amblyopia, visual acuity improvement in the amblyopic eye by $\geq 2$ Log MAR lines, and adherence at $95 \%$ confidence interval (Cl). The directions of effect were computed from two hours to six hours patching, part-time patching to full-time patching, and from patching to atropine. Forest plots were constructed for each study and pooled data (The squares and horizontal lines correspond to the study-specific risk ratio or mean difference at $95 \%$ confidence interval; the diamond represents the pooled risk ratio or mean difference at $95 \%$ Confidence interval; $p$-value indicates the level of significance; $I^{2}$ indicates the percentage of total statistical variation of effect sizes across the studies). Sources of variability or heterogeneity that results in distortion of the analysis and misleading were cautioned. The effect of methodological heterogeneity (variability related with trial design and quality) and clinical heterogeneity (Variability related with the participants' age, the types or timing of outcome measurements, and intervention) were assured by performing risk of bias assessment and considering subgroup analysis, moderator variables analysis and Meta-regression analysis, respectively.

Moreover, statistical heterogeneity or variability in summary treatment effects between trials was tested during result pooling. Quantitative data pooling or Meta - analysis was considered for studies with low or moderate statistical heterogeneity $\left(I^{2}<50 \%, p>0.05\right)$ using the fixed-effect models. ${ }^{40,41}$ The qualitative synthesis was performed for pooled studies with significant statistical heterogeneity. The analysis was computed using review manager 5.3 and Comprehensive Meta-analysis version 2.

\section{Results}

\section{Literature search}

Altogether, 1892 records were retrieved from an electronic database and manual searching. After the removal of duplicated records, 1592 records were exposed for abstract screening, and 48 articles appeared to be relevant for full-text review. After full-text review, 41 articles were excluded due to various reasons. The remaining 8 articles passed the eligibility criteria, and all of them were included in qualitative and quantitative synthesis (Figure1). ${ }^{15,37-39,42-45}$

\section{Characteristics of included studies}

Eight randomized controlled trials with the total of 1253 participants were included. The mean age of the participants was ranged from $4.8 y e a r s$ to $13.6 y e a r s$. Majority of the studies used a logMAR chart even if some of them presented the visual acuity in Snellen's decimal and fraction (Table1). ${ }^{39,42}$

\section{Quality assessment (Risk of bias and publication bias)}

The risk of bias assessment was conducted based on the pre-specified criteria. The majority of the studies were free of allocation concealment bias (75\%), random sequence generation ( $88 \%)$, attrition bias (88\%), reporting bias $(100 \%)$ and other potential bias (100\%). However, a significant portion of the trials did not disclose blinding of participants (88\%) and detection bias (38\%) (Figure 2 and Figure 3). The supportive evidence for the author's judgment was documented (Table 2). Publication bias was evaluated for trials that compared patching with atropine. It indicated that nearly all studies appeared on the top of the funnel plot and they were symmetrically distributed with respect to the weighted mean, which was also supported by Egger's regression intercept (Bo= $-0.5 ; 95 \% \mathrm{Cl}-2.12$ to $1.09 ; \mathrm{p}$-value=0.3). Though publication bias is an unavoidable issue in a review article, it was not too foreboding for this review (Figure 4 )

\section{Effect of interventions}

\section{Comparison of patching interventions}

Totally four clinical trials compared different spectrum of patching modalities starting from two hours patching per day to full time patching ${ }^{15,38,43,45}$. A total of 518 children were enrolled whose pooled mean age was 6.25 years. All studies consisted of children with amblyopia associated with either anisometropia or strabismus or mixed. Two studies conducted on children with moderate amblyopia ${ }^{38,45}$. The remaining two trails enrolled children with severe amblyopia 43 , and mixed amblyopia (children with moderate and severe degree of amblyopia) ${ }^{15}$. The pooled mean time that studies measured the outcome of intervention was 4 month of follow up 15,38,43,45. Majority of the studies used Electronic-ETDRS chart to measure the visual acuity ${ }^{38,43,45}$. Overall, it is noted that there are some extent of baseline variation of enrolled participants related to cause and degree of amblyopia.

Regarding the modality of intervention, one clinical trial compared the effectiveness of 2 hours patching and 6 hours patching for moderate mixed amblyopia, and the mean baseline visual acuity of amblyopic in both groups was 0.48 Log MAR unit ${ }^{38}$. This study reported that $79.3 \%$ of the participants from two hours patching and $76.4 \%$ of the participants from the six hours patching improved their visual acuity of the amblyopic eye by $2 \geq \log$ MAR lines from the baseline. The mean visual acuity improvement of amblyopic eye from the baseline was $2.4 \pm 1.34$ lines in 2 hours patching group and $4 \pm 1.61$ lines in 6 hours patching group. The mean difference between the group is zero $(\mathrm{MD})=0.00 ; 95 \% \mathrm{Cl},-0.45$ to 0.45 ). Hence, the author concluded both treatment modalities were equally effective for moderate amblyopia. 
Stewart et al ${ }^{45}$ also compared that the visual acuity improvement in the amblyopic eye in six hours and full-time patching in children with moderate amblyopia after 3.5 months of follow up. The baseline BCVA of both groups was $0.45 \mathrm{log}$ MAR unit. Post-treatment visual acuity improvements of amblyopic eye were $2.6 \pm 1.9$ lines in six hours patching and $2.4 \pm 2.4$ lines in full-time patching. The effectiveness difference was not statistically significant (MD, $0.2 ; 95 \%$ $\mathrm{Cl},-0.75$ to 1.15 ). Similarly, Singh et al ${ }^{15}$ compared the effectiveness of 2 hours patching, 4hours patching, and 6hours patching and full time patching and the baseline visual acuity of amblyopic eye were $0.67,0.8,0.68$ and 0.76 Log MAR unit, respectively. The author reported that the four groups were matched for age, distribution of the three types of amblyopia and pre-treatment BCVA. Post-treatment visual acuity improvements of amblyopic eye from the baseline were $1.7 \pm 1$. 1 lines in 2 hours patching, $2.6 \pm 1$.7lines in 4hours patching, $3 \pm 1$.6lines in 6 hours patching and $3.6 \pm 2.2$ lines, which was compared with pretreatment visual acuity. Hence, the study showed that significant visual improvement in all four groups has been achieved. Furthermore, regardless of the severity of amblyopia, a significantly better outcome was seen when visual improvement in full time patching, six hours patching and four hours patching group were compared with two hours patching. However, statistically significant effectiveness difference between four hours, six hours and full time patching groups was not evident. This study also compared the effectiveness difference for in mild- moderate and severe amblyopia amblyopia separately. The author concluded that all grades of patching are equally effective for mild to moderate amblyopia in children. However, significantly better visual outcome was achieved in six hours and full-time group as compared to four and two hours for severe amblyopia. Both Singh et al ${ }^{15}$ and Stewart et al ${ }^{45}$ did not measure the success of treatment in the manner of visual acuity improvement of the amblyopic eye by $2 \geq \log$ MAR lines from the baseline.

PEDIG $2003 b^{43}$ compared the effectiveness of six hours patching and full time patching for treating severe amblyopia.The average baseline BCVA of amblyopic eye was 0.9 logMAR in six hour patching and $0.89 \log$ MAR in full time patching group. This study revealed that $93 \%$ of the participants from six hours patching and $84.5 \%$ of the participants from the full-time patching improved their visual acuity of the amblyopic eye by $2 \geq$ log MAR lines from the baseline. The mean visual acuity improvement after 4 month of follow up was $4.8 \pm 2.3$ lines in 6 hours patching group and $4.7 \pm 2.9$ lines in full time patching (MD, $0.1 ; 95 \% \mathrm{Cl},-0.71$ to 0.91 ). Thus the author concluded that six hours of daily patching and full-time patching are equally successful in visual acuity improvement.

Furthermore, PEDIG 2003a indicated that the incidence of reverse amblyopia was $6.5 \%$ (6/92 cases) in 2 hours and $8.9 \%$ ( $8 / 89$ cases) in 6 hours patching. The proportion of participants achieved good adherence was $83 \%$ for 2 hours group and $74 \%$ for 6 hours patching group ${ }^{38}$. PEDIG $2003 \mathrm{~b}$ also reported higher reverse amblyopia in the full-time group (11\%) as compared to six hours patching groups (4\%). Singh et al ${ }^{15}$ and Stewart et al ${ }^{45}$ did not report reverse amblyopia and adherence.

Overall, the finding of the four studies implies that the severity of amblyopia matters the effectiveness a certain of patching regimen. Qualitatively, the learntlesson is that all grades of patching, from 2 hours to full time patching, are equally effective in treating mild to moderate amblyopia. However, only 6 hours patching to full-time patching regimen are effective for severe amblyopia. Regardless of the severity of amblyopia, the effectiveness of three clinical trials that compared six-hours patching with full time patching was pooled ${ }^{15,43,45}$. In Singh et al ${ }^{15}$ only participants enrolled in Six hours patching and full-time patching group was considered for meta-analysis. The weighted mean visual acuity improvement of amblyopic eye was similar for both groups. The effectiveness difference was nearly zero (MD, $0.00 ; 95 \% \mathrm{Cl},-0.54$ to 0.55$)$, which indicates that the pooled synthesis is in agreement with the qualitative synthesis (Figure 5). Furthermore, the incidence rate of reverse amblyopia is directly related with dose of patching despite less conclusive. Therefore, these findings drive a new insight that six hours patching is an optimal choice that balances the primary and secondary outcomes of patching intervention for various degree of functional amblyopia management, particularly severe amblyopia.

\section{Comparison of Patching with atropine}

Four clinical trials compared the effectiveness of patching with atropine $37,3942,44$. A total of 664 participants were enrolled whose pooled mean age was 9.3 years. Of them, two studies compared part-time patching (2hours patching) with atropine and they measured the visual acuity improvement at 4.25 month of follow up. ${ }^{39,44}$. The remaining two trials compared full-time patching with atropine and the outcome was measured at $6 \mathrm{month}$ of follow up. ${ }^{37,42}$.All trials measured the visual acuity improvement as an outcome using ETDRS vision chart.

PEDIG $2002{ }^{37}$ studied the visual acuity improvements in full time patching and atropine group for children with moderate amblyopia associated with either anisometropia or strabismus or mixed. The baseline BCVA was 0.53 Log MAR unit. At 6month of follow up, $87 \%$ of participants in patching group and $82.5 \%$ of participants in atropine improved their visual acuity of amblyopic eye by $2 \geq$ Log MAR lines from the baseline (RR, $1.06 ; 95 \%$ Cl; 0.97 to 1.15$)$. The mean visual acuity improvement of amblyopic eye was $3.16 \pm 1.6$ lines in patching group and $2.84 \pm 1.6$ lines in atropine group. Statistically significant betterment was seen in patching groups as compared to atropine (MD 0.32; $95 \% \mathrm{Cl} ; 0.01$ to 0.63 ).

Similarly, PEDIG $2008^{39}$ compared the effectiveness of two hours patching with atropine penalization in children with moderate mixed amblyopia. The baseline BCVA was 0.48 Log MAR unit. At 4.25 month of follow, $45 \%$ of participants in two hour patching group and $40 \%$ in atropine improved their visual acuity of amblyopic eye by $2 \geq$ Log MAR lines from the baseline (RR,1.14; $95 \% \mathrm{Cl} ; 0.8$ to 1.61 ). The mean visual acuity improvement was $1.72 \pm 1.56$ lines in two hours group and 1.52 \pm 2.1 lines in atropine group. Significant effectiveness difference was not seen between the modalities (MD=0.2 at $95 \%-0.26,0.66)$.

The remaining two clinical trials investigated the effectiveness of patching and atropine in treating severe and mixed amblyopia 42,44 . PEDIG 200944 compared two hours patching with atropine in children with severe amblyopia. The baseline BCVA was 0.95 Log MAR unit. After 17 weeks of treatment, $54 \%$ in two hours patching group and $40 \%$ in atropine improved visual acuity of the amblyopic eye by $2 \geq \log$ MAR lines from the baseline (RR, 1.35 ; $95 \%$ Cl; 0.61 to

2.81). The visual acuity of amblyopic eye was improved by $1.8 \pm 1.3$ lines in two hours patching and $1.5 \pm 2.1$ lines in atropine group. Both modalities produced similar improvement, (MD 0.3, at $95 \% \mathrm{Cl},-0.86$ to 1.46). One trial studied the treatment outcome of full time patching and atropine in children with mixed anisometropic amblyopia ${ }^{42}$. The baseline BCVA was nearly $0.64 \log$ MAR units in both groups. At 6 month of follow up, the visual acuity of amblyopic eye of 
improved by $2.38 \pm 1.19$ lines in patching group and $2.34 \pm 1.14$ lines in atropine from the baseline. Statistically significant difference between the modalities was not found (MD=0.04, at $95 \% \mathrm{Cl}-0.56$ to 0.64$)$.

Three trails reported incidence of developing reverse of amblyopia $37,39,44$. PEDIG $2002{ }^{37}$ reported that $1.4 \%$ of participants in patching and $8.7 \%$ in atropine groups have developed reverse amblyopia. The variation was statistically significant (RR, $0.16 ; 95 \% \mathrm{Cl} ; 0.05$ to 0.55 ). Likewise, PEDIG 200944 revealed a single case of reverse amblyopia from atropine group but no cases from patching (RR, $0.5 ; 95 \% \mathrm{Cl} ; 0.02$ to 11.42 ). PEDIG 2008 reported that there was no incidence of reverse amblyopia in both groups ${ }^{39}$. The combined incidence of developing reverse amblyopia was lower by $19 \%$ for patching groups as compared to atropine (RR, $0.19 ; 95 \% \mathrm{Cl}: 0.06,0.57$ ). With regard to adherence, $83 \%$ of the participants from patching group and $96 \%$ from atropine group achieved the level of good adherence ${ }^{37}$. Even though majority of the participants from both intervention were within the level of good adherence, it was noted that atropine is statistically favorable (RR, $0.87,95 \% \mathrm{Cl} ; 0.81$ to 0.93 ). Similarly, PEDIG 2008 reported that $84 \%$ of the participants from atropine group and $80 \%$ of participants from patching (RR $0.95,95 \% \mathrm{Cl} ; 0.82$ to 1.09$){ }^{39}$. However, Menon et al 2008 found that adherence was slightly better in patching (62\%) than atropine group (57\%) but it was not statistically significant variation (RR, 1.09, 95\% Cl; 0.71 to 1.67$).{ }^{42}$

Therefore, regardless of the severity of amblyopia, the two hours patching and atropine produces similar visual acuity improvement. Even though the degree and significance of visual acuity improvement seems slightly better in full time patching as compared to atropine, it is inconclusive. Hence, the quantitative synthesis may resolve the controversy, in which the pooled estimate indicated that patching was statistically favorable to atropine (MD, 0.25 lines; $95 \% \mathrm{Cl}, 0.01$ to 0.48 ) (Figure 6). Besides, the weighted estimate of improving visual acuity in the amblyopic eye by $\geq 2$ log MAR lines was better in patching group (74.1\%\%) than atropine $(67.2 \%)(\mathrm{RR}, 1.08 ; 95 \% \mathrm{Cl}, 0.98$ to 1.18). On the other hand, the incidence of developing reverse amblyopia was lower in patching groups as compared to atropine (RR, $0.19 ; 95 \% \mathrm{Cl}: 0.06,0.57)$. Even if there was disagreement between the authors, the pooled estimate of adherence is better in atropine, (RR, 0.9; $95 \% \mathrm{Cl}, 0.84$ to 0.96$)$ (Figure 7 ).

\section{Moderator variables and Subgroup analysis}

Severity of amblyopia, the cause of amblyopia, a dose of patching and age of the participants were considered as moderator variables. The pooled mean visual acuity between part-time (2hours patching) patching and atropine was 0.21 lines ( $95 \% \mathrm{Cl},-0.21$ to 0.64 ), which was not significantly different. Similarly, for trials that compared full time patching with atropine, the mean post-treatment visual acuity different was 0.26 lines ( $95 \% \mathrm{Cl}$, -0.02 to 0.54 ), which was not also significant(Figure 6). ${ }^{37,42}$ Hence, the effectiveness difference between patching and atropine was not explained by the variation of the patching dose. The Meta-regression analysis showed that the effectiveness difference for patching and atropine did not associate with age ( $\mathrm{B} 0=-0.03 ; \mathrm{a}=0.5 ; \mathrm{p}=0.4)$ (Figure 8 ). Regardless of the cause of amblyopia, Singh et al found that part-time patching and full-time patching can produce a similar visual outcome for mild to moderate amblyopia. However, in severe amblyopia, six hours and full-time occlusion treatment were significantly more effective than two hours occlusion ${ }^{15}$. It was also noted that there was no significant difference between 6 hours and full time patching for severe amblyopia. Furthermore, PEDIG $2003^{\mathrm{a}}$ indicated that the mean visual acuity improvement in strabismus, anisometropic, and mixed amblyopia was similar for both modalities. ${ }^{40}$

\section{Discussion}

Overall, the pooled mean visual acuity improvement of amblyopic eye was similar for both groups (MD, $0.00 ; 95 \% \mathrm{Cl},-0.54$ to 0.55 ). All grades of patching are equally effective in treating mild to moderate amblyopia. However, only 6 hours patching to full-time patching regimen are effective for severe amblyopia. This implies that the severity of amblyopia affects the choice of patching regimen. Even if full time patching is effective for mild to moderate amblyopia, the incidence of reverse amblyopia should be under consideration. Therefore, these findings drive a new insight that six hours patching is an optimal choice that balances the primary and secondary outcomes of patching intervention for various degree of functional amblyopia management under consideration of clinical heterogeneity related to some extent baseline variability. Evidence related to adherence and reverse amblyopia in patching treatment need furthers investigation.

Regarding atropine versus patching, majority of the trials concluded that both treatment modalities are equally effective independently. However, the quantitative synthesis estimated that patching was statistically favorable to atropine (MD, 0.25 lines; $95 \% \mathrm{Cl}, 0.01$ to 0.48 ). Besides, the incidence of developing reverse amblyopia was lower in patching groups as compared to atropine (RR, $0.19 ; 95 \% \mathrm{Cl}: 0.06,0.57)$. The pooled estimate of adherence is better in atropine, (RR, $0.9 ; 95 \% \mathrm{Cl}, 0.84$ to 0.96$)$. This implies that patching could provide better visual acuity improvement with minimal incidence of reverse amblyopia. This finding is contrary to a study that found conventional occlusion and atropine produce comparable visual acuity improvement in the amblyopic eye and concluded atropine penalization as first line treatment for amblyopia. ${ }^{27}$ As a subgroup analysis, this review found that effectiveness difference between patching and atropine is not explained by the variation of the patching dose, severity of amblyopia and age at the time enrollment.

The effort invested to evaluate the benefit and harms of each intervention is the good stand of this review despite data limitation. Moreover, serious caution was taken while selecting the studies; particularly those studies conducted on residual amblyopia, outcome measurement methods and time, and visual acuity stabilization with optical correction. Though publication bias and risk of bias are an unavoidable issue in a review article, it was not too foreboding. The majority of the studies were RCT trial, which is free of allocation concealment bias, random sequence generation, attrition bias and reporting bias, which minimizes methodological heterogeneity and validates the appropriateness of the synthesis. Even if the majority of included trials free from the risk of bias, blinding of the participants was not clearly disclosed in some studies. Since cost-effectiveness synthesis is not considered, economically efficient treatment modality is not implicated.

This review also did not include active or interactive amblyopia treatments which require the interaction of patients with the treatment like a video game, vision therapy, and near activities even though there are substantial research revolution on such amblyopia treatment modlaities. Hence, this area would be potential 
for future researches who interest to generate evidence. Moreover, this study did not aim to find which interventions provide rapid improvement.

Overall, this systematic review implicated that the choice of amblyopia treatment should rely on both primary and secondary outcomes. Selection of the modality depends on the severity of amblyopia. This review also indicates that atropine and full-time patching should be given under close follow up to prevent reverse amblyopia. Treatment adherence is related to patching dose. As a result, strong physician-parents integration might be crucial for maximizing the adherence rate and adverse effects.

\section{Conclusions}

Patching, paticullary six-hours patching,provides optimal visual acuity improvement for severe amblyopia that balances the effect of reverse amblyopia and poor adhrence as compared to atropine and other spectrum of patching regimen. All spectrum of patching less than six hour patching are equally effective for mild to moderate amblyopia and minimize the side effects related to reverse amblyopia and poor adherence as compared to atropine and six hours to full-time patching regimen.

\section{Abbreviations}

BCVA, Best Corrected Visual Acuity; Log MAR, Logarithm of minimum angle of resolution; PEDIG, Pediatric Eye disease Investigative Group; FTO, Full time Occlusion; PTO, Part time Occlusion; RCT, Randomized controlled Trail; MD, Mean difference; Cl confidence Interval; RR, Relative risk; I $^{2}$ describes the percentage of total variation across studies; SD, standard deviation; the US, United States; UK, United Kingdom; MA, Mixed amblyopia; AA, Anisometropia amblyopia; MAR, the minimum angle of resolution; hrs, hours; yrs, years; VA, visual; ETDRS, Early Treatment Diabetic Retinopathy Study

\section{Declarations}

Ethical approval and consent for participant: Since this manuscript is a review article, ethical approval and consent for participant is not applicable.

Consent for publication: Since this manuscript does not include individual data, consent for publication is deemed not required.

Availability of data and materials: The datasets used and/or analyzed during the current study available from the corresponding author on reasonable request

Competing interests: None of the above authors have any proprietary interests or conflicts of interest related to this submission.

Funding: This work is not financed by any organization.

Author's Contributions: All authors conceived, designed the study and analyzed the data. NF. and GT. retrieved the articles, screened the articles, extracted relevant data ,assessed the risk of bias for included articles. MS and AA wrote the first draft of the article. Finally, All authors read and approved the final manuscript.

Acknowledgement: Not Applicable

\section{References}

1. Gilbert, C. E. \& Ellwein, L. B. Prevalence And Causes Of Functional Low Vision In School-Age Children: Results From Standardized Population Surveys In Asia, Africa, And Latin America. Invest Ophthalmol Vis Sci 2008; 49: 877-881.

2. Chia, A., Dirani, M., Chan, Y.-H., et al Prevalence Of Amblyopia And Strabismus in Young Singaporean Chinese Children. Invest Ophthalmol Vis Sci 2010; 51:3411-3417.

3. Faghihi, M., Hashemi, H., Nabovati, P., et al . The Prevalence Of Amblyopia And Its Determinants In A Population-Based Study. Strabismus 2017; 25:176183.

4. Hashemi, H., Yekta, A., Jafarzadehpur, E.,, et al. The Prevalence of Amblyopia In 7-Year-Old Schoolchildren In Iran. Strabismus 2014; $22: 152-7$.

5. Polling, J. R., Loudon, S. E. \& Klaver, C. C. Prevalence of Amblyopia and Refractive Errors in an unscreened Population of Children. Optom Vis Sci 2012; 89: E44-9.

6. Rajavi, Z., Sabbaghi, H., Baghini, A. S., et al . Prevalence Of Amblyopia And Refractive Errors Among Primary School Children. J Ophthalmic Vis Res 2015; 10: 408-416.

7. Xiao, O., Morgan, I. G., Ellwein, L. B. \& He, M. Prevalence of Amblyopia in School-aged Children and variations by age, gender, and Ethnicity in a MultiCountry Refractiv Error Study. Ophthalmology 2015; 122,:1924-1931.

8. Tailor, V., Bossi, M., Greenwood, J. A. \& Dahlmann-Noor, A. Childhood Amblyopia: Current Management And New Trends. Br Med Bull 2016; 119;:75-86.

9. Hou, C., Pettet, M. W. \& Norcia, A. M. Acuity-Independent Effects Of Visual Deprivation On Human Visual Cortex. Proc Natl Acad Sci U S A 2014; 111: E3120-8.

10. Bretas, C. C. \& Soriano, R. N. 2016. Amblyopia: Neural Basis And Therapeutic Approaches. Arq Bras Oftalmol 2016;79: 346-351.

11. Hussain, Z., Svensson, C.-M., Besle, J., Webb, B. S., Barrett, B. T. \& Mcgraw, P. V. Estimation Of Cortical Magnification From Positional Error In Normally Sighted And Amblyopic Subjects. J Vis 2015; 15: 25-25.

12. Van Leeuwen, R., Eijkemans, M. J., Vingerling, J. R., Hofman, A., De Jong, P. T. \& Simonsz, H. J. Risk of Bilateral Visual Impairment in Persons with Amblyopia: The Rotterdam Study. Br J Ophthalmol 2007; 91: 1450-1

Page $7 / 15$ 
13. Walle, D. K., Repka, M. X., Lee, K. A.,et al. Amblyopia Preferred Practice Pattern(R). Ophthalmology 2018; 125:105-142.

14. PEDIATRIC EYE DISEASE INVESTIGATOR GROUP.Atropine Vs Patching For Treatment Of Moderate Amblyopia: Follow-Up At 15 Years of age of A Randomized Clinical Trial. JAMA Ophthalmol 2014;132: 799-805.

15. Singh, I. Sachdev N, Brar GS, Kaushik S. 2008. Part-Time Occlusion Therapy For Amblyopia in older children. Indian J Ophthalmol 2008; 56:459.

16. Astle, A. T., Mcgraw, P. V. \& Webb, B. S. 2011. Can Human Amblyopia Be Treated in Adulthood? Strabismus 2011; $19: 99-109$.

17. Mccoy, P. A., Huang, H.-S. \& Philpot, B. D. Advances In Understanding Visual Cortex Plasticity. Curr Opin Neurobiol 2009; 19: $298-304$.

18. Roper-Hall, G. Current Concepts of Amblyopia: A Neuro-Ophthalmology Perspective. Am Orthopt J 2007; 57:2-12.

19. Asper, L., Watt, K. \& Khuu, S. Optical Treatment of Amblyopia: A Systematic Review And Meta-Analysis. Clin Exp Optom 2018; 101: 431-442.

20. Kirandi, E. U., Akar, S., Gokyigit, B., Onmez, F. E. A. \& Oto, S. Risk Factors For Treatment Failure And Recurrence Of Anisometropic Amblyopia. Int Ophthalmol 2017; 37:835-842.

21. Patwardhan, N. A. Is Age Relevant For The Success Of Treatment Of Anisometropic Amblyopia? Int J Ophthalmol 2007; 55: 469-470.

22. Flynn JT, S. J., Feuer W, Corona A. The Therapy Of Amblyopia: An Analysis Of The Results of Amblyopia Therapy Utilizing The Pooled Data Of Published Studies. Trans Am Ophthalmol Soc 1998; 96: 431-50.

23. Scott, W. E. \& Dickey, C. F. Stability of Visual Acuity In Amblyopic Patients After Visual Maturity. Graefes Arch Clin Exp Ophthalmol 1988;226: 154-157.

24. Stewart, C. E., Fielder, A. R., Stephens, D. A. \& Moseley, M. J. Treatment Of Unilateral Amblyopia: Factors Influencing Visual Outcome. Invest Ophthalmol Vis Sci 2005; 46: 3152-3160.

25. Toor, S. S., Horwood, A. M. \& Riddell, P. M. Anisometropic Amblyopia: Factors Influencing The Success or Failure of Its Treatment. Br Ir Orthopt J 2015;9: 916.

26. Woodruff F, H. F., Thompson Jr, Smith Lk. Factors Affecting The Outcome of Children Treated For Amblyopia. Eye 1994; 8: 627-31.

27. Li T, S. K. Conventional Occlusion Versus Pharmacologic Penalization For Amblyopia. Cochrane Database of Systematic Reviews 2009; CD006460

28. Yazdani, N., Sadeghi, R., Momeni-Moghaddam, H., Zarifmahmoudi, L., Ehsaei, A. \& Barrett, B. T. Part-Time Versus Full-Time Occlusion Therapy For Treatment Of Amblyopia: A Meta-analysis. J Curr Ophthalmol 2017;29: 76-84.

29. Patil, P. A., Meenakshi, S. \& Surendran, T. S. Refractory Reverse Amblyopia With Atropine Penalization. Oman J Ophthalmol 2010; 3: 148-149.

30. Kane, J., Biernacki, R., Fraine, L., Fukuda, N., Haskins, K. \& Morrison, D. G. Patching Compliance With Full-Time Vs. Part-Time Occlusion Therapy. Am Orthopt J 2013; 63:19-23

31. Foley-Nolan, A., Mccann, A. \& O’keefe, M. Atropine Penalisation Versus Occlusion As The Primary Treatment For Amblyopia. Br J Ophthalmol 1997; 81: 5457.

32. Tejedor, J. \& Ogallar, C. Comparative Efficacy Of Penalization Methods In Moderate To Mild Amblyopia. Am J Ophthalmol 2008; $145: 562-569$.

33. Arikan, G., Yaman, A. \& Berk, A. T. Efficacy of occlusion treatment in amblyopia and clinical risk factors affecting the results of treatment. Strabismus 2005; 13: 63-69.

34. Liberati, A., Altman, D. G., Tetzlaff, J., et al. The Prisma Statement For Reporting Systematic Reviews And Meta-Analyses of Studies That Evaluate Health Care Interventions: Explanation And Elaboration. PLoS Med $2009 ; 6:$ E1000100.

35. Cochrane Collaboration. Data Collection Form For Intervention Reviews: RCTs And Non-RCTs.Http://Training.Cochrane.Org/Resource/Data-CollectionFormsIntervention reviews 2014.

36. Quinn, G. E., Melia, B. M. \& Group, P. E. D. I. How Does One Define Success In Amblyopia Treatment? Invest Ophthalmol Vis Sci $2009 ; 50: 4697-4697$.

37. PEDIATRIC EYE DISEASE INVESTIGATOR GROUP. A Randomized Trial Of Atropine Vs. Patching For Treatment Of Moderate Amblyopia In Children. Arch Ophthalmol 2002; 120: 268-78.

38. PEDIATRIC EYE DISEASE INVESTIGATOR GROUP. A Randomized Trial of Patching Regimens For Treatment of Moderate Amblyopia In Children. Arch Ophthalmol 2003a; 121: 603-11.

39. PEDIATRIC EYE DISEASE INVESTIGATOR GROUP. Patching Vs Atropine to Treat Amblyopia In Children Aged 7 To 12 Years: A Randomized Trial. Arch Ophthalmol 2008; 126: 1634-42.

40. Higgins Jpt, G. S. E. Cochrane Handbook For Systematic Reviews Of Interventions Version 5.1.0 [Updated March 2011]. The Cochrane Collaboration, 2011. Available From Http://Handbook.Cochrane.Org .

41. Higgins JP, Thompson SG, Deeks JJ, Altman DG. Measuring inconsistency in meta-analyses. BMJ. 2003 Sep 6;327(7414):557-60. doi: 10.1136/bmj.327.7414.557. PMID: 12958120; PMCID: PMC192859.

42. Menon, V., Shailesh, G., Sharma, P. \& Saxena, R. Clinical Trial Of Patching Versus Atropine Penalization For The Treatment Of Anisometropic Amblyopia In Older Children. J AAPOS 2008; 12: 493-7.

43. PEDIATRIC EYE DISEASE INVESTIGATOR GROUP. A Randomized Trial Of Prescribed Patching Regimens For Treatment Of Severe Amblyopia In Children. Ophthalmology 2003b; 110: 2075-87.

44. PEDIATRIC EYE DISEASE INVESTIGATOR GROUP. Treatment of Severe Amblyopia With Weekend Atropine: Results From 2 Randomized Clinical Trials. J AAPOS 2009; 13: 258-263.

45. Stewart, C. E., Stephens, D. A., Fielder, A. R. \& Moseley, M. J. Objectively Monitored Patching Regimens For Treatment Of Amblyopia: Randomised Trial. BMJ 2007; 335: 707-707.

\section{Tables}


Table 1: Characteristics of included studies (the astrik * indicates that the data were obtained after pooling the mean of the groups)

\begin{tabular}{|c|c|c|c|c|c|c|c|c|}
\hline Studies & $\begin{array}{l}\text { Study } \\
\text { Design, } \\
\text { location } \\
\end{array}$ & $\begin{array}{l}\text { Age and } \\
\text { sex }\end{array}$ & $\begin{array}{l}\text { Cause of } \\
\text { Amblyopia }\end{array}$ & $\begin{array}{l}\text { Severity } \\
\text { of } \\
\text { amblyopia }\end{array}$ & $\begin{array}{l}\text { Length of } \\
\text { follow up }\end{array}$ & $\begin{array}{l}\text { Comparison type: } \\
\text { sample size }\end{array}$ & $\begin{array}{l}\text { Baseline mean VA in the } \\
\text { amblyopic eye }\end{array}$ & VA chart us \\
\hline $\begin{array}{l}\text { PEDIG } \\
2003^{a}\end{array}$ & RCT,USA & $\begin{array}{l}5.2 \text { yrs } \\
\text { Male :106 } \\
\text { Female: } 83\end{array}$ & MA & Moderate & 4months & $\begin{array}{l}\text { 2hrs } \\
\text { patching:92cases } \\
6 \text { hrs } \\
\text { patching:89cases }\end{array}$ & $\begin{array}{l}\text { 2hours: } 0.48 \text { log MAR } \\
\text { 6hours: } 0.48 \text { log MAR }\end{array}$ & $\begin{array}{l}\text { Electronic- } \\
\text { ETDRS }\end{array}$ \\
\hline $\begin{array}{l}\text { PEDIG } \\
2003^{b}\end{array}$ & RCT,USA & $\begin{array}{l}\text { 4.8yrs } \\
\text { Male:94 } \\
\text { Female: } 81\end{array}$ & MA & Severe & 4months & $\begin{array}{l}\text { PTO(6hrs):73cases } \\
\text { FTO:84caes }\end{array}$ & $\begin{array}{l}\text { PTO: } 0.9 \log \text { MAR } \\
\text { FTO:0.89log MAR }\end{array}$ & $\begin{array}{l}\text { Electronic- } \\
\text { ETDRS }\end{array}$ \\
\hline $\begin{array}{l}\text { Stewart } \\
\text { et al } \\
2007\end{array}$ & RCT,UK & $\begin{array}{l}5.6 y r s \quad \text { Not } \\
\text { Sex } \\
\text { reported }\end{array}$ & MA & Moderate & $>3.5$ months & $\begin{array}{l}\text { PTO }(6 \mathrm{hrs}): 40 \text { case } \\
\text { FTO }(12 \mathrm{hrs}): 40 \text { case }\end{array}$ & $\begin{array}{l}\text { PTO:0.45log MAR } \\
\text { FTO:0.44logMAR }\end{array}$ & $\begin{array}{l}\text { ETDRS } \\
\text { chart(Log } \\
\text { MAR) }\end{array}$ \\
\hline $\begin{array}{l}\text { Singh } \\
\text { et al } \\
2008\end{array}$ & RCT,USA & $\begin{array}{l}9.43 * \text { Sex } \\
\text { not } \\
\text { reported }\end{array}$ & MA & Mixed & 4.5months & $\begin{array}{l}2 \text { hrs.: } 25 \text { case } \\
4 \text { hrs.: } 25 \text { cases } \\
6 \text { hrs:25cases } \\
\text { FTO:25cases }\end{array}$ & $\begin{array}{l}\text { 2hours:0.67logMAR units } \\
\text { 4hours:0.80logMAR units } \\
\text { 6hours:0.68logMAR units } \\
\text { FTO: } 0.76 \text { log MAR }\end{array}$ & $\begin{array}{l}\text { Carl Ze } \\
\text { chart } \\
\text { projector(Sz } \\
\text { 350)Convert } \\
\text { to Log MAR }\end{array}$ \\
\hline $\begin{array}{l}\text { Menon } \\
\text { et al } \\
2008\end{array}$ & $\begin{array}{l}\mathrm{RCT}, \\
\text { India }\end{array}$ & $\begin{array}{l}13.6^{*} \\
\text { Male:28 } \\
\text { Female:29 }\end{array}$ & AA & Mixed & 6months & $\begin{array}{l}\text { Atropine: } 28 \text { cases } \\
\text { FTO:29cases }\end{array}$ & $\begin{array}{r}\text { Atropine:0.228(decimal) } \\
\text { (0.642logMAR) } \\
\text { Patching:0.22(decimal) } \\
(0.655 \log M A R) \\
\end{array}$ & $\begin{array}{l}\text { ETDRS } \\
\text { chart(Log } \\
\text { MAR) }\end{array}$ \\
\hline $\begin{array}{l}\text { PEDIG } \\
2002\end{array}$ & RCT,USA & $\begin{array}{l}\text { 5.3yrs } \\
\text { Male:223 } \\
\text { Female:196 }\end{array}$ & MA & Moderate & 6months & $\begin{array}{l}\text { Atropine:194cases } \\
\text { FTO:208cases }\end{array}$ & $\begin{array}{l}\text { Atropine:0.53logMAR } \\
\text { FTO:0.52 Log MAR }\end{array}$ & $\begin{array}{l}\text { Electronic } \mathrm{L} \\
\text { MAR chart }\end{array}$ \\
\hline $\begin{array}{l}\text { PEDIG } \\
2009\end{array}$ & RCT,USA & $\begin{array}{l}9.3 y r s \\
\text { Male:24 } \\
\text { Female:16 } \\
\end{array}$ & MA & Severe & 4.25 month & $\begin{array}{l}\text { Atropine:20cases } \\
\text { PTO }(2 \mathrm{hrs}): 13 \text { cases }\end{array}$ & $\begin{array}{l}0.95 \text { log MAR for both } \\
\text { groups }\end{array}$ & $\begin{array}{l}\text { Electronic- } \\
\text { ETDRS }\end{array}$ \\
\hline $\begin{array}{l}\text { PEDIG } \\
2008\end{array}$ & RCT,USA & $\begin{array}{l}\text { 9yrs } \\
\text { Male:91 } \\
\text { Female:102 } \\
\end{array}$ & MA & Moderate & 4.25 month & $\begin{array}{l}\text { Atropine:88cases } \\
\text { PTO }(2 \mathrm{hrs}):: 84 \\
\text { cases }\end{array}$ & $\begin{array}{l}\text { Mean VA: } 20 / 63 \text { for both } \\
\text { groups (0.489 log MAR) }\end{array}$ & $\begin{array}{l}\text { Electronic- } \\
\text { ETDRS }\end{array}$ \\
\hline
\end{tabular}

Table 2: Supportive evidence for risk of bias assessment 


\begin{tabular}{|c|c|c|}
\hline Menon et al 2008 & $\begin{array}{l}\text { Status } \\
\text { category }\end{array}$ & Evidence \\
\hline \multirow{2}{*}{$\begin{array}{l}\text { Random sequence } \\
\text { generation } \\
\text { Allocation } \\
\text { concealment }\end{array}$} & $\begin{array}{l}\text { unclear } \\
\text { risk }\end{array}$ & $\begin{array}{l}\text { "Stratified randomization was used to place patients in these } 2 \text { groups depending on the visual acuity of } \\
\text { patients at presentation." }\end{array}$ \\
\hline & $\begin{array}{l}\text { unclear } \\
\text { risk }\end{array}$ & $\begin{array}{l}\text { "Stratified randomization was used to place patients in these } 2 \text { groups depending on the visual acuity of } \\
\text { patients at presentation." }\end{array}$ \\
\hline $\begin{array}{l}\text { Blinding of } \\
\text { participants and } \\
\text { personnel }\end{array}$ & $\begin{array}{l}\text { Unclear } \\
\text { risk }\end{array}$ & Not reported \\
\hline $\begin{array}{l}\text { Blinding } \\
\text { outcome } \\
\text { assessment }\end{array}$ & $\begin{array}{l}\text { Unclear } \\
\text { risk }\end{array}$ & Not reported \\
\hline $\begin{array}{l}\text { Incomplete } \\
\text { outcome data }\end{array}$ & Low risk & $9 \%$ attrition. It was acceptable. \\
\hline $\begin{array}{l}\text { Selective } \\
\text { reporting }\end{array}$ & Low risk & No selective reporting \\
\hline Other bias & Low risk & Both groups were comparable at baseline. \\
\hline \multicolumn{3}{|l|}{ PEDIG 2003a } \\
\hline $\begin{array}{l}\text { Random sequence } \\
\text { generation }\end{array}$ & Low risk & $\begin{array}{l}\text { "Randomization was accomplished on the studies web site's using a permuted block design of varying } \\
\text { blocks size" }\end{array}$ \\
\hline $\begin{array}{l}\text { Allocation } \\
\text { concealment }\end{array}$ & Low risk & $\begin{array}{l}\text { It is not explicitly stated 'allocation was concealed' in PEDIG publications, but publications did state that } \\
\text { participants were randomized using the PEDIG website, which means the allocations were concealed. }\end{array}$ \\
\hline $\begin{array}{l}\text { Blinding } \\
\text { participants }\end{array}$ & $\begin{array}{l}\text { Unclear } \\
\text { risk }\end{array}$ & Not reported \\
\hline $\begin{array}{l}\text { Blinding } \\
\text { outcome } \\
\text { assessment } \\
\end{array}$ & Low risk & $\begin{array}{l}\text { "Visual acuity testing was conducted by a study-certified vision tester who was masked to the patient's } \\
\text { treatment group." }\end{array}$ \\
\hline $\begin{array}{l}\text { Incomplete } \\
\text { outcome data }\end{array}$ & Low risk & 4\% attrition, which was acceptable. \\
\hline $\begin{array}{l}\text { Selective } \\
\text { reporting }\end{array}$ & Low risk & No selective reporting \\
\hline Other bias & Low risk & Both groups were comparable at baseline and used large sample size. \\
\hline \multicolumn{3}{|l|}{ PEDIG 2002} \\
\hline \multirow{2}{*}{$\begin{array}{l}\text { Random sequence } \\
\text { generation } \\
\text { Allocation } \\
\text { concealment }\end{array}$} & Low risk & $\begin{array}{l}\text { "Randomization was accomplished on the studies web site's using a permuted block design of varying } \\
\text { blocks size" }\end{array}$ \\
\hline & Low risk & $\begin{array}{l}\text { Randomization was accomplished on the } \\
\text { study's web site", which is one form of central } \\
\text { allocation }\end{array}$ \\
\hline $\begin{array}{l}\text { Blinding } \\
\text { participants }\end{array}$ & $\begin{array}{l}\text { unclear } \\
\text { risk }\end{array}$ & "Not reported." \\
\hline $\begin{array}{l}\text { Blinding } \\
\text { outcome } \\
\text { assessment }\end{array}$ & Low risk & $\begin{array}{l}\text { "Visual acuity testing was conducted by a study-certified vision tester who was masked to the patient's } \\
\text { treatment group." }\end{array}$ \\
\hline $\begin{array}{l}\text { Incomplete } \\
\text { outcome data }\end{array}$ & Low risk & $4 \%$ attrition, which was acceptable. \\
\hline $\begin{array}{l}\text { Selective } \\
\text { reporting }\end{array}$ & Low risk & No selective reporting \\
\hline Other bias & isk & th groups were comparable at baseline and used large sample size. \\
\hline
\end{tabular}

\section{PEDIG 2003b}

Random sequence generation Allocation concealment Blinding participants Blinding outcome assessment Incomplete outcome data Selective reporting Other bias

\section{PEDIG 2008}

Random seque generation Allocation concealment Blinding participants Blinding outcome
Randomization was accomplished on the study's website using a permuted-blocks design of varying block sizes."

Low It is not explicitly stated 'allocation was concealed' in PEDIG publications, but publications do state that risk participants were randomized using the PEDIG website, which means the allocations were concealed.

of Unclear Not reported risk

of Low risk "At the 4-month outcome examination, visual acuity testing was conducted by a study-certified vision tester who was masked to the patient's treatment group."

Low risk Attrition 10\%

Low risk No selective reporting

Low risk Both groups were comparable.

quence Low risk "Each subject were randomly assigned using a permuted blocks design."

Low risk It is not explicitly stated 'allocation was concealed' in PEDIG publications, but publications do state that participants were randomized using the PEDIG website, which means the allocations were concealed

of Unclear Not reported risk

of low risk "The examiner was masked to treatment group" 


\begin{tabular}{|c|c|c|}
\hline $\begin{array}{l}\text { Incomplete } \\
\text { outcome data }\end{array}$ & Low risk & Attrition $11 \%$ \\
\hline $\begin{array}{l}\text { Selective } \\
\text { reporting }\end{array}$ & Low risk & No selective reporting \\
\hline Other bias & Low risk & Both groups were comparable. \\
\hline \multicolumn{3}{|l|}{ PEDIG 2009} \\
\hline $\begin{array}{l}\text { Random sequence } \\
\text { generation }\end{array}$ & Low risk & Probably done but not reported \\
\hline $\begin{array}{l}\text { Allocation } \\
\text { concealment }\end{array}$ & $\begin{array}{l}\text { Low } \\
\text { risk }\end{array}$ & $\begin{array}{l}\text { It is not explicitly stated 'allocation was concealed' in PEDIG publications, but publications do state that } \\
\text { participants were randomized using the PEDIG website, which means the allocations were concealed }\end{array}$ \\
\hline $\begin{array}{l}\text { Blinding of } \\
\text { participants }\end{array}$ & $\begin{array}{l}\text { Unclear } \\
\text { risk }\end{array}$ & Not reported \\
\hline $\begin{array}{l}\text { Blinding } \\
\text { outcome } \\
\text { assessment }\end{array}$ & $\begin{array}{l}\text { Low } \\
\text { risk }\end{array}$ & Outcome assessor was masked. \\
\hline $\begin{array}{l}\text { Incomplete } \\
\text { outcome data }\end{array}$ & $\begin{array}{l}\text { High } \\
\text { risk }\end{array}$ & Greater attrition $17 \%$ \\
\hline $\begin{array}{l}\text { Selective } \\
\text { reporting }\end{array}$ & Low risk & No selective reporting \\
\hline Other bias & Low risk & Both groups were comparable. \\
\hline \multicolumn{3}{|l|}{ Singh et al 2008} \\
\hline $\begin{array}{l}\text { Random sequence } \\
\text { generation }\end{array}$ & Low risk & They were randomized using computer-generated random numbers." \\
\hline $\begin{array}{l}\text { Allocation } \\
\text { concealment }\end{array}$ & $\begin{array}{l}\text { Unclear } \\
\text { risk }\end{array}$ & Not reported \\
\hline $\begin{array}{l}\text { Blinding of } \\
\text { participants }\end{array}$ & $\begin{array}{l}\text { Unclear } \\
\text { risk }\end{array}$ & Not reported \\
\hline $\begin{array}{l}\text { Blinding of } \\
\text { outcome } \\
\text { assessment }\end{array}$ & $\begin{array}{l}\text { Unclear } \\
\text { risk }\end{array}$ & Not reported \\
\hline $\begin{array}{l}\text { Incomplete } \\
\text { outcome data }\end{array}$ & Low risk & No attrition \\
\hline $\begin{array}{l}\text { Selective } \\
\text { reporting }\end{array}$ & Low risk & No selective reporting \\
\hline Other bias & Low risk & had comparable groups \\
\hline \multicolumn{3}{|l|}{ Stewart et al } \\
\hline $\begin{array}{l}\text { Random sequence } \\
\text { generation }\end{array}$ & Low risk & $\begin{array}{l}\text { "children with prescribed dose rates of either } 12 \text { hours a day or six hours a day using a random number } \\
\text { generator" }\end{array}$ \\
\hline $\begin{array}{l}\text { Allocation } \\
\text { concealment }\end{array}$ & Low risk & There was allocation concealment \\
\hline $\begin{array}{l}\text { Blinding of } \\
\text { participants }\end{array}$ & $\begin{array}{l}\text { Unclear } \\
\text { risk }\end{array}$ & Neither investigator nor the parents were masked to group allocation \\
\hline $\begin{array}{l}\text { Blinding of } \\
\text { outcome } \\
\text { assessment }\end{array}$ & $\begin{array}{l}\text { Unclear } \\
\text { risk }\end{array}$ & Not reported \\
\hline $\begin{array}{l}\text { Incomplete } \\
\text { outcome data }\end{array}$ & Low risk & No attrition \\
\hline $\begin{array}{l}\text { Selective } \\
\text { reporting }\end{array}$ & Low risk & No selective reporting \\
\hline Other bias & Low risk & Enrolled comparable groups \\
\hline
\end{tabular}

\section{Figures}




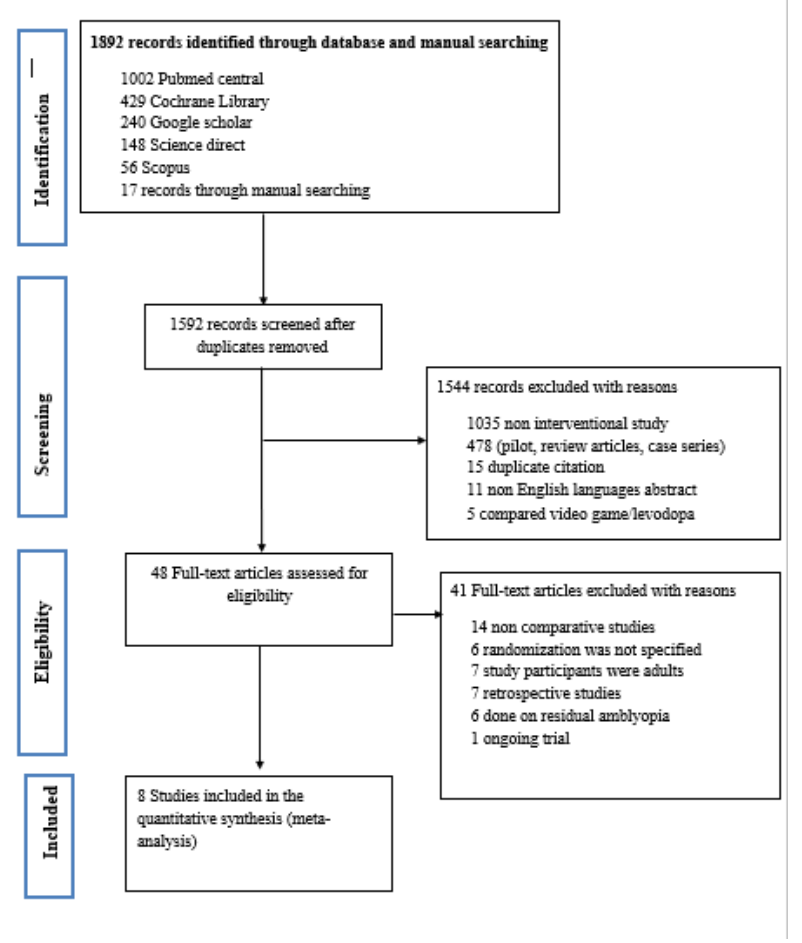

Figure 1

PRISMA flow diagram showing the literature searching and selection process

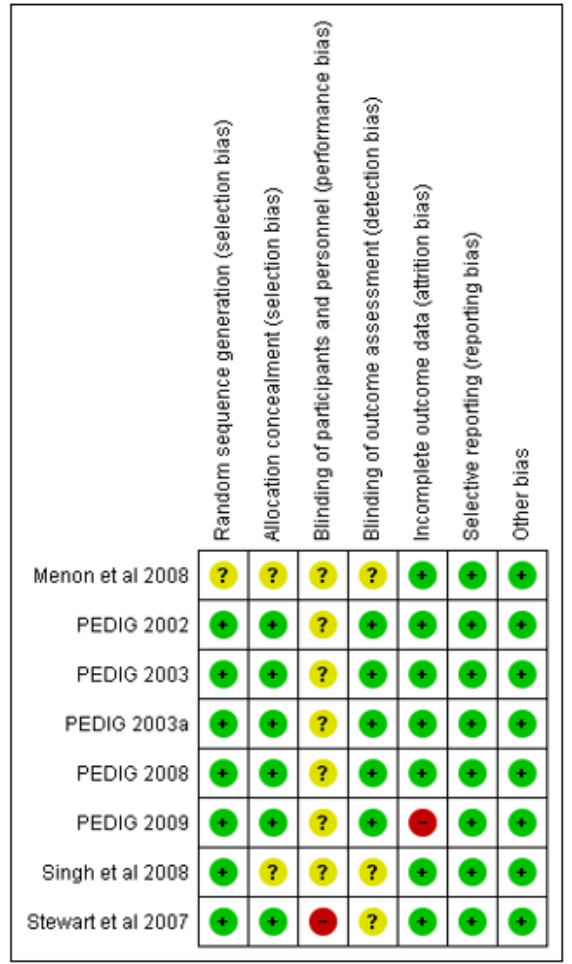

Figure 2

Assessment of risk of bias using Cochrane Collaboration Tool (The plus sign, indicates low risk; the red, indicates high risk; the question mark, indicates unclear risk) 


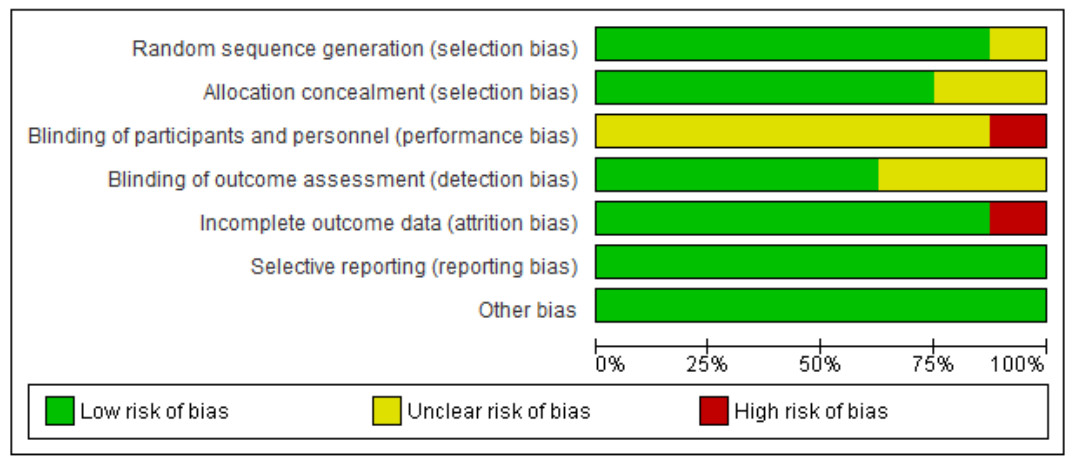

\section{Figure 3}

Summative assessment of the risk of bias (Number of studies=8)

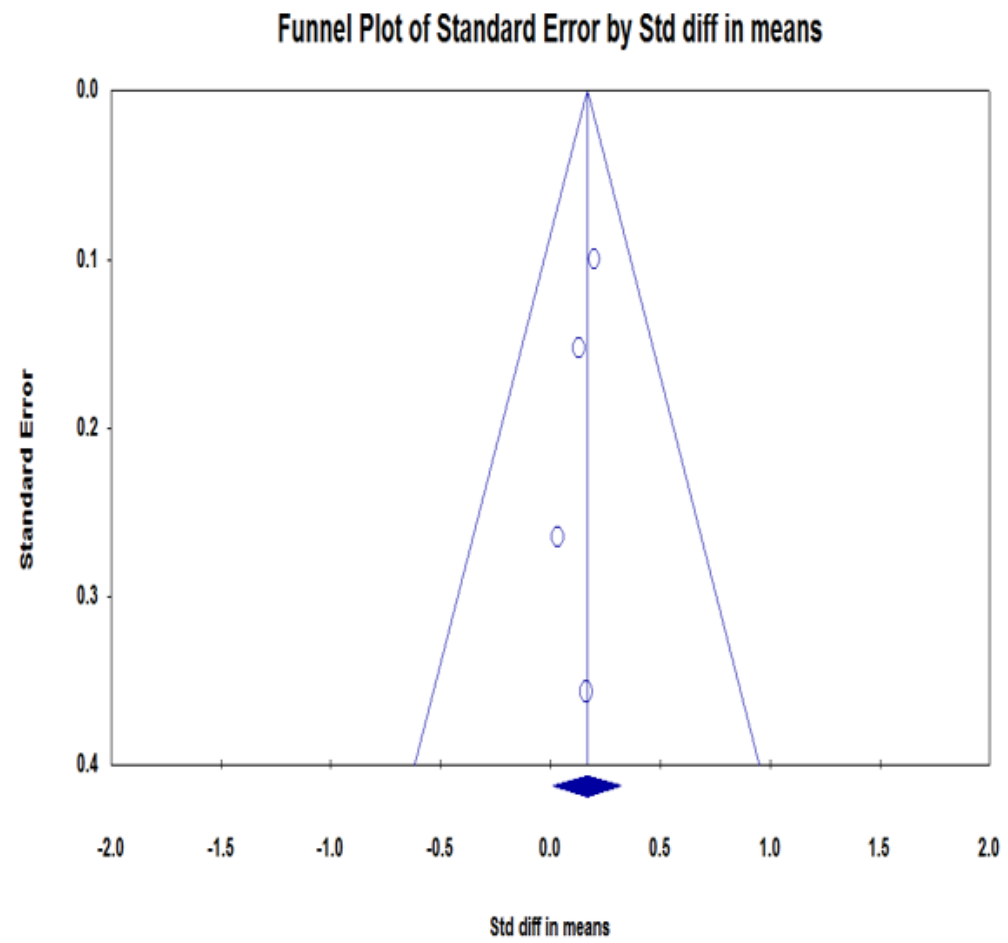

\section{Figure 4}

Funnel plot showing publication bias across the studies (The diamond indicates weighted mean difference value; the circles indicate the mean difference of each study)

Part time patching Full time patching Mean Difference Mifference

Study or Subgroup Mean [line] SD [line] Total Mean [line] SD [line] Total Weight IV, Fixed, $95 \%$ CI [line] 2.1.1 Mean visual acuity improvement from the baseline

$\begin{array}{lrrrrrrrr}\text { PEDIG 2003b } & 4.8 & 2.3 & 73 & 4.7 & 2.9 & 84 & 44.9 \% & 0.10[-0.71,0.91] \\ \text { Singh et al 2008 } & 3 & 1.6 & 25 & 3.5 & 2.5 & 25 & 22.0 \% & -0.50[-1.66,0.66] \\ \text { Stewart et al 2007 } & 2.6 & 1.9 & 40 & 2.4 & 2.4 & 40 & 33.1 \% & 0.20[-0.75,1.15] \\ \text { Subtotal (95\% Cl) } & & & 138 & & & 149 & 100.0 \% & 0.00[-0.54,0.55]\end{array}$

Heterogeneity. $\mathrm{Ch}^{2}=0.94, \mathrm{df}=2(P=0.63) ; 1^{2}=0 \%$

Test for overall effect: $Z=0.00(P=1.00)$

Total (95\% Cl)

138

Heterogeneity $\mathrm{Chi}^{2}=0.94, \mathrm{df}=2(\mathrm{P}=0.63) ;{ }^{2}=0 \%$

Test for overall effect: $Z=0.00(P=1.00)$

Test for subqroup differences: Not applicable
$149100.0 \% \quad 0.00[-0.54,0.55]$

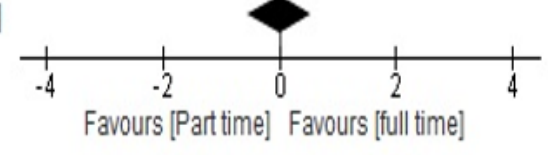


Figure 5

The visual acuity improvement in the amblyopic eye after part-time ( 6 hours) versus full-time patching (The squares and horizontal lines correspond to the study-specific mean difference and $95 \%$ confidence interval; the diamond represents the pooled mean difference; $p$-value indicates the level of significance; 12 indicates the percentage of total variation across studies)

Patching Atropine Mean Difference Mean Difference

Study or Subgroup Mean [line] SD [line] Total Mean [line] SD [line] Total Weight IV, Fixed, $95 \%$ Cl [line] $\quad$ IV, Fixed, $95 \%$ Cl [line]

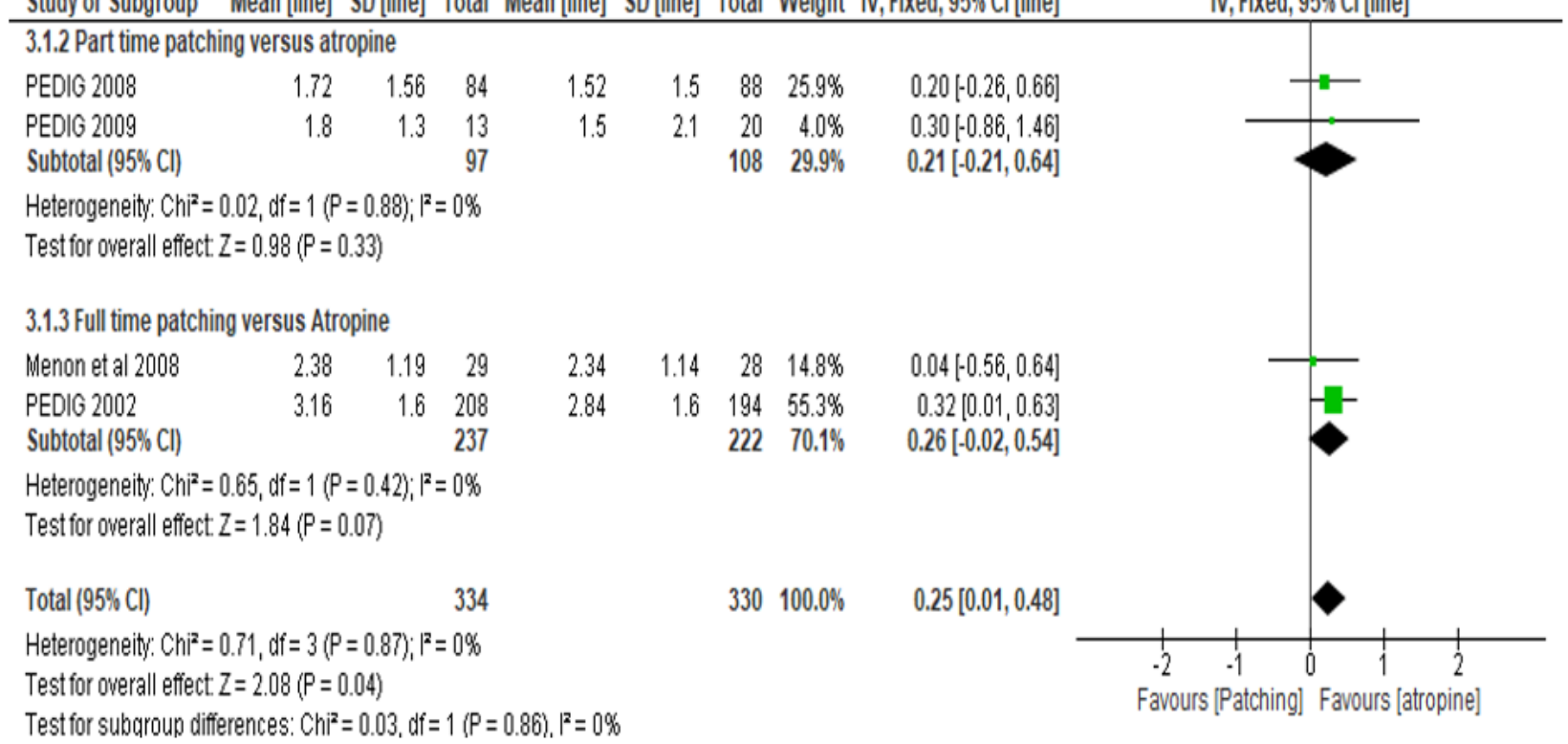

\section{Figure 6}

The visual acuity improvement in the amblyopic eye after patching versus atropine

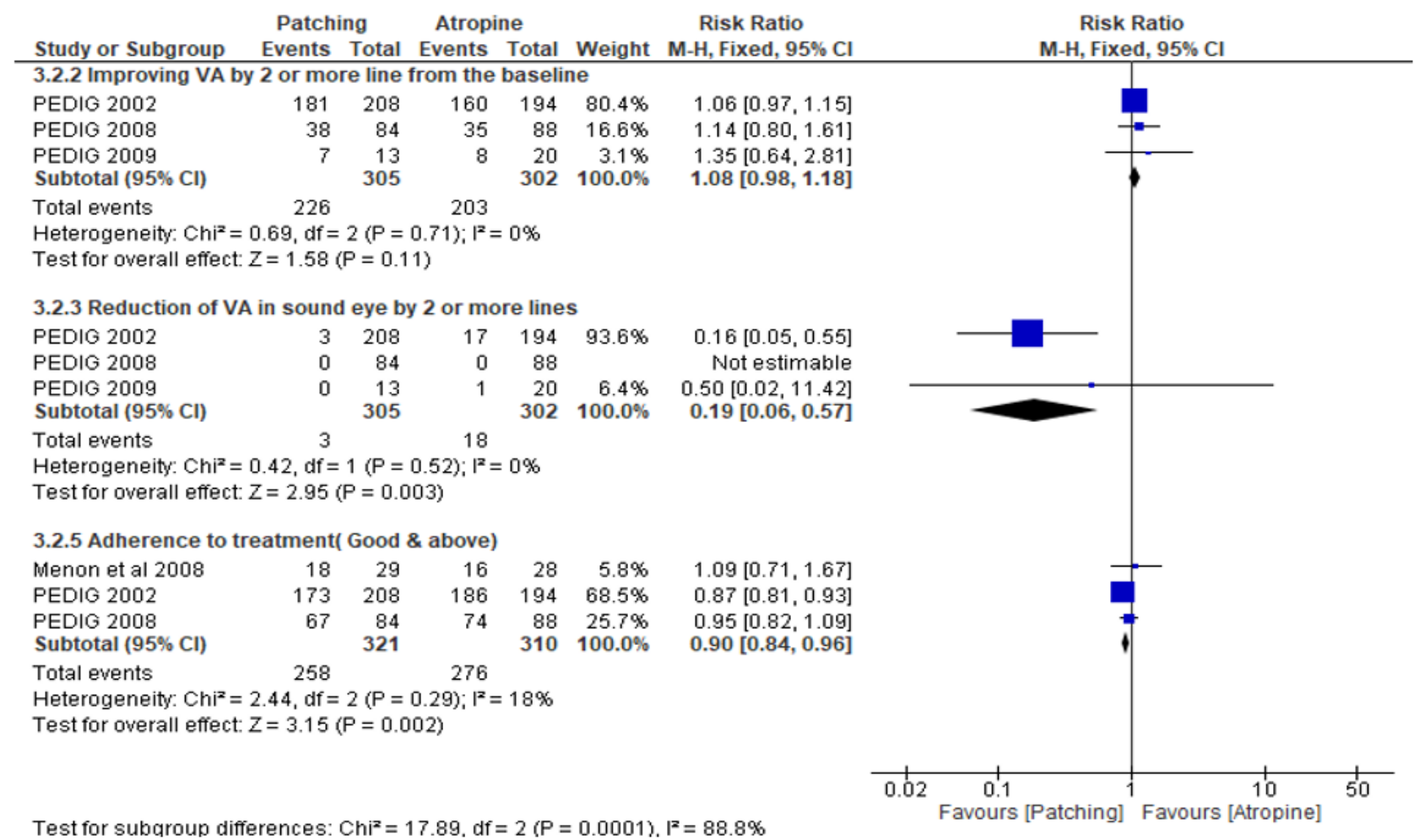

\section{Figure 7}

The success, adherence and incidence rate of reverse amblyopia in patching versus atropine 


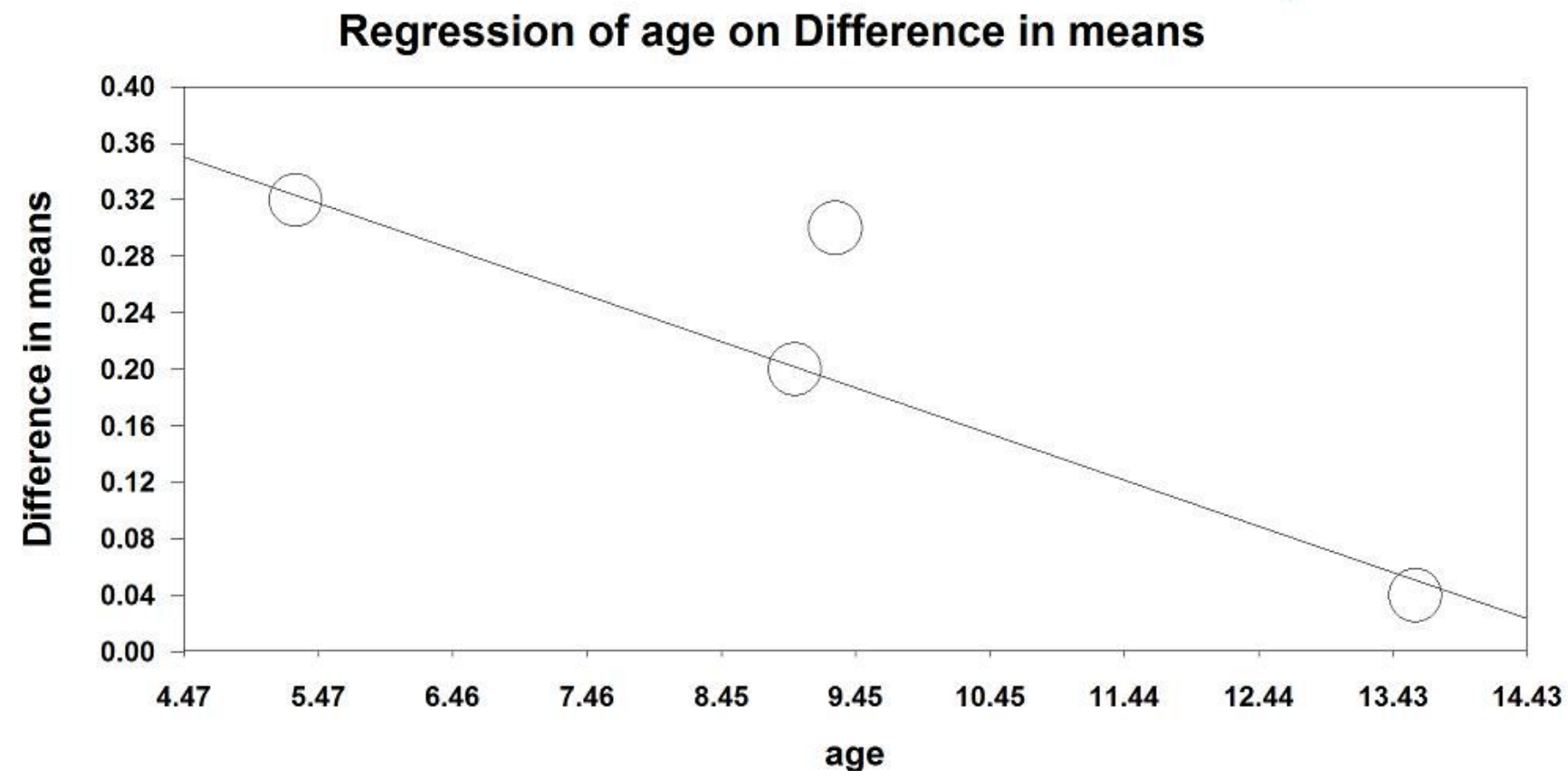

Figure 8

Meta-regression analysis showing the effect of age on the effectiveness of patching and atropine

\section{Supplementary Files}

This is a list of supplementary files associated with this preprint. Click to download.

- PRISMA2009ChecklistMSWord.doc

- Supplementary.docx 